their charge to die without any attempt at medical treatment have not as yet aroused public attention owing to their scarcity. But that the movement is spreading in this country cannot be doubted.

To the public at large this so-called "science" would be of comparatively little interest were it a mere religion pure and simple. Its interest-and, I may add, its danger-lies in that it professes to be much more than a religion: it claims to hold the keys of health, to check disease, and to place the patient under treatment on the high road to health, not by drugs or any physical method of treatment, but simply by a sustained effort of the will. To us with all the elaborate mechanism of modern science at our disposal, and the painfully accumulated clinical experience of centuries at our back, this may seem the veriest charlatanism to be dismissed on a priori grounds as a palpable absurdity. But we find-not in this country but in the "States"-that there are over one million people bold enough to claim from their own experience benefit from this method. Their statements are a factor whose influence on public opinion cannot be ignored; and a brief account of the methods of "Christian Science" may therefore serve some useful purpose. To do this I must first describe the phenomena of "suggestion" and "auto-suggestion." Every hospital resident knows that when a patient for any reason has been treated with sleeping draughts or hypodermics of morphia for some little time he can readily be made to go to sleep by feigning to give him his usual draught, substituting any harmless placebo or giving a hypodermic of sterilised water instead of morphia. The idea of sleep is induced in his mind by the performance and he rapidly quiets down into natural slumber. This and many cognate phenomena come under the head of "natural suggestion."

An analogous but more powerful form is what is known as "hypnotic suggestion." It is not much practised in this country and need not further be referred to. "Auto-suggestion," as its name would imply, is where the idea emanates from the patient himselï. He has made up his mind that certain things will happen and within limits they do. Any practitioner who has seen cholera abroad will tell you that when an epidemic starts those who are most afraid of taking it almost invariably do. The explanation, of course, is that the vibrios are already present in the intestines (just as one often finds the diphtheritic bacillus in swabs from the throats of healthy people during an epidemic of diphtheria), but the resistance of the tissues has been lowered by fear and the individual who might otherwise have escaped becomes a victim under the influence of auto-suggestion.

Bearing these two phenomena in mind the methods of the "Christian Scientist" are easily explained. To take a concrete example. A Christian Scientist gets a headache. Instead of looking for sympathy he sits down calmly and repeats a formula something like this: "I have no pain. There is no pain. I feel no pain. There is no such thing as pain. Nothing is real but mind. There is no pain. By keeping his mind fixed on this one idea he states that presently the pain is gone. Now if one comes to analyse his method it is at once seen to be one of pure "auto-suggestion." In a similar manner by "natural suggestion" one can work on the feelings and beliefs of others. Hysterical aphonia, imitative chorea, \&c, can readily be treated and, in fact, are treated regularly in everyday practice by the exercise of a strong will over a weaker. The success of many a practitioner is largely due to his hopeful manner with his patients He sets them thinking, not of how ill they are, but of how soon they will get better. And this is exactly the method of the Christian Scientist. He works by "diverting his mind from unhealthy channels and compelling it to travel in healthy ones." In the jargon of his religion he calls it " right thinking" in contra-distinction to "wrong thinking," which is the origin of all unhappiness and disease according to his view.

Backed by the glamour and mystery of a new religion it is obvious what a powerful weapon he wields against imaginary ailments and all the protean forms of hysteroidal and hypochondriacal fancies. But it is here the danger begins. He is not content to stop here. He claims to be able to cure all diseases by this method. But, unfortunately, the most powerful forms of suggestion will not reduce a strangulated hernia or all the thinking in the world stop the insidious course of the tubercle bacillus. As long as the Christian Scientist contents himself with treating the thousand-and-one small ailments which affect the mind rather than the body he serves a useful purpose, for faith based on any foundation, no matter how dubious, is always powerful. But when he professes to cure diseases of which he can have no practical knowledge-diseases in which there is some distinct pathological lesion-he immediately becomes a danger to the State and a person to be avoided as one would the plague.

March 21st, 1903

I am, Sirs, yours faithfully, J. JOHNSTON ABRAHAM.

\section{SHORTENING THE SACRO-UTERINE LIGA- MENT IN THE TREATMENT OF PROLAPSUS UTERI.}

\section{To the Editors of THE LANCET.}

SIRS,-Mr. E. Stanmore Bishop in his admirable paper on shortening the sacro-uterine ligaments in the treatment of prolapsus uteri in THE LANCET of March 14th, p. 725, has most courteously alluded to my paper read before the British Gynæcological Society upon the same subject. In theory his operation and mine are identically the same, but in practice, as he points out, they differ in one or two important points. Mr. Stanmore Bishop does not suspend the uterus at all to the abdominal wall; his objection to this is the fact that if the uterus is so attached by "ventrofixation" serious difficulties may arise in the future. Now in my opinion "ventro-fixation" is a misnomer ; it should be termed "ventro-suspension," as in my experience I do not think it possible to fix the uterus absolutely to the abdominal parietes without the fundus is fastened directly to the recti muscles, but so long as it is only attached to the peritoneum no fixation will take place, as it will be found, as I have proved, that the attachments are always half an inch or more long and composed solely of peritoneal tissues which readily stretch. The importance of this attachment is, I think, that if the sacro-iliac ligaments are shortened without some parietal attachment to the fundus there is considerable risk of the uterus becoming strongly anteverted and to the patient in consequence being subject to all the inconvenience appertaining to this condition.

The rationale of the operation is readily understood if one considers that the uterus is a motile body suspended by the lateral ligaments and maintained in its normal antero-posterior position mainly by the sacro-uterine ligaments. Should these ligaments become weakened the uterus has a tendency to revolve backwards on its axis, the broad ligaments, thus throwing more and more strain upon their posterior attachments which, continuing to elongate, eventually drag the fundus completely round, causing retroversion. The uterus, now lying in the axis of the vagina and the supports from above being weakened and elongated, gradually becomes more and more prolapsed and if the perineal supports are weakened or perhaps non-existing it is readily seen that there is nothing to prevent the whole organ prolapsing. The only natural way of restoring the organ to its normal position is unquestionably to repair those attachments which in its normal state keep it in position and the chief of these unquestionably are the posterior attachments or those which suspend the os and cervix posteriorly and which tend to keep the uterus in the antero-posterior position; this can only be done by passing a couple or three sutures deeply into the tissues on each side of the rectum in the position of the sacro-uterine ligaments, bringing these forward so as to pass through the peritoneum and subperitoneal tissues in two or three places, and catching the cervix of the uterus; the two ends are then tied firmly. The elongated and sacculated pouch of Douglas is by a darning stitch puckered up and a firm suspensory ligament formed. In many cases colpoperineoplasty will have to be performed, but even without this, if sacro-uterine suspension be properly performed, I am convinced that the uterus may be retained in its proper position.

I am, Sirs, yours faithfully, Frederic Bowreman JessetT. Brook-street, W., March 23rd, 1903.

\section{A NEW ILLUMINANT FOR THE FUNDUS OCULI. \\ To the Editors of THE LANCET.}

SrRs, - The large number of red rays reflected from the fundus of the eye when examining it by the ordinary light tends to mask some of the detail ; this is especially the case 